\title{
Prognostic implications of ventricular fibrillation in acute myocardial infarction: new strategies required for further mortality reduction
}

\author{
J W Sayer, R A Archbold, P Wilkinson, S Ray, K Ranjadayalan, A D Timmis
}

\begin{abstract}
Objective-To determine the changing risk of ventricular fibrillation, the prognostic implications, and the potential long term prognostic benefit of earlier hospital admission, after acute myocardial infarction.

Design-Prospective observational study.

Setting-A district general hospital in east London.

Patients-1225 consecutive patients admitted to a coronary care unit with acute myocardial infarction.

Main outcome measures-Time of onset of pain and ventricular fibrillation, and long term survival of patients admitted with acute myocardial infarction.

Results-The rate of ventricular fibrillation in these hospital inpatients was high in the first hour from onset of pain (118 events/1000 persons/h; 95\% confidence interval (CI) 50.7 to 231) and fell rapidly to an almost constant low level by six hours; $27.4 \%$ of patients with early ventricular fibrillation died in hospital, compared with $11.6 \%$ of those without ( $p<0.0001)$, but mortality in patients who survived to hospital discharge was not altered by early ventricular fibrillation (five year survival: $75.0 \%(95 \%$ CI $60.0 \%$ to $84.8 \%)$ with ventricular fibrillation $v 73.3 \%$ (95\% CI $69.6 \%$ to $76.6 \%$ ) without ventricular fibrillation).

Conclusions-Patients successfully resuscitated from early ventricular fibrillation have the same prognosis as those without ventricular fibrillation after acute myocardial infarction. Faster access to facilities for resuscitation must be achieved if major improvements in the persistently high case fatality of patients after acute myocardial infarction are to be made.

(Heart 2000;84:258-261)
\end{abstract}

Epidemiology Unit,

London School of

Hygiene and Tropical

Medicine, Keppel

Street, London WC1,

Keywords: ventricular fibrillation; acute myocardial infarction; prognosis

UK

P Wilkinson

Department of Cardiology, Newham General Hospital, Glen

Road, London E13, UK

S Ray

K Ranjadayalan

Correspondence to: Dr Timmis

email: adam@

timmis-lch.demon.co.uk

Accepted 7 December 1999

Over the last 25 years there have been significant advances in the treatment of patients with acute myocardial infarction but little improvement in case fatality at the population level. Case fatality remains $15-20 \%$ in patients with acute myocardial infarction admitted to hospital, ${ }^{12}$ and $45 \%$ when patients who die out of hospital are considered. ${ }^{3}$ Of those under the age of 55 years dying from acute myocardial infarction, as many as $90 \%$ may die outside hospital. ${ }^{3}$ Data such as these show the potential limitations of further improvements in hospital treatment. Despite this, efforts to improve the outcome of patients with acute myocardial infarction have over-

Table 1 Characteristics of 1225 patients admitted with acute myocardial infarction

\begin{tabular}{|c|c|c|}
\hline Demographics & $\begin{array}{l}\text { No ventricular } \\
\text { fibrillation }(n=1113)\end{array}$ & $\begin{array}{l}\text { Ventricular } \\
\text { fbrillation }(n=112)\end{array}$ \\
\hline Age (median (interquartile range)) & $62(54$ to 70$)$ & 65 (57 to 72$)$ \\
\hline Men & $829(74.5 \%)$ & $71(63.4 \%)$ \\
\hline Diabetes $\star$ & $232(20.8 \%)$ & $18(16.1 \%)$ \\
\hline White & $819(73.6 \%)$ & $98(87.5 \%)$ \\
\hline Smokers $\dagger$ & $572(51.4 \%)$ & $63(56.3 \%)$ \\
\hline $\mathrm{Q}$ wave infarcts $\ddagger$ & $846(76.0 \%)$ & $95(84.8 \%)$ \\
\hline \multicolumn{3}{|l|}{ Treatments } \\
\hline Thrombolysis and aspirin & $755(67.8 \%)$ & $54(48.2 \%)$ \\
\hline Thrombolysis & $59(5.3 \%)$ & $9(8.0 \%)$ \\
\hline Aspirin & $211(19.0 \%)$ & $26(23.2 \%)$ \\
\hline Neither & $71(6.4 \%)$ & $19(17.0 \%)$ \\
\hline Data incomplete for thrombolysis or aspirin & $17(1.5 \%)$ & $4(3.6 \%)$ \\
\hline \multicolumn{3}{|l|}{ Complications } \\
\hline Left ventricular failure $\$$ & $71(33.3 \%)$ & $53(47.3 \%)$ \\
\hline Hospital death & $132(11.7 \%)$ & $32(28.6 \%)$ \\
\hline
\end{tabular}

*Unrecorded in three patients without ventricular fibrillation; funrecorded in 23 patients without and one patient with ventricular fibrillation; łunrecorded in nine patients without and three patients with ventricular fibrillation; Sunrecorded in five patients without ventricular fibrillation. whelmingly concentrated on their treatment once they have reached hospital (arrhythmia monitoring, thrombolysis, primary angioplasty). The number of patients with acute myocardial infarction who die before hospital admission from ventricular fibrillation (and could therefore perhaps be saved) is unknown, but is likely to be considerable. We present evidence from a district general hospital that emphasises the substantial reductions in fatality that are theoretically achievable by accelerating patient access to expert medical care.

\section{Methods}

STUDY POPULATION

The study group comprised all 1225 consecutive patients admitted to the coronary care unit of a district general hospital in the east end of London from 1 January 1988 to 31 December 1994 with acute myocardial infarction (table 1). The diagnosis required two of the following three criteria: cardiac chest pain lasting at least 30 minutes; ECG changes of myocardial infarction with $\geqslant 0.1 \mathrm{mV}$ ST elevation in at least one standard lead or $\geqslant 0.2 \mathrm{mV}$ ST elevation in two or more contiguous chest leads; a diagnostic rise in creatine kinase to $\geqslant 400 \mathrm{IU} / 1$ (upper limit of reference range $200 \mathrm{IU} / 1$ ).

\section{DATA COLLECTION}

Baseline clinical data, including the date and time of onset of chest pain, racial group, clinical history, smoking habits, examination 
findings, ECG data, serum potassium (admission blood sample), cardiac enzyme concentrations, and details of treatment, were collected prospectively, as were episodes of ventricular fibrillation (defined as early if within 48 hours) and left ventricular failure. The diagnosis of left ventricular failure required symptoms of breathlessness with either basal crepitations or a third heart sound, requiring treatment with diuretics. Diabetes was recorded if the patient required insulin, oral hypoglycaemic drugs, or dietary restriction.

FOLLOW UP

Survival to hospital discharge was recorded for all 1225 patients. Information on mortality to October 1995 and cause of death was obtained by tracing through the Office for National Statistics. Reliable matches could not be made for 68 patients, but follow up data were obtained in 52 of these from hospital or general practitioner records or by direct inquiry. Thus follow up beyond hospital discharge was obtained in 1209 of the 1225 patients $(98.7 \%$; median duration 953 days).

DATA ANALYSIS

Rates of ventricular fibrillation (first episodes of ventricular fibrillation/person-hour at risk) were calculated by hour from the onset of chest pain. A polynomial Poisson regression curve fitted to these rates was used for graphical presentation only. Multivariate predictors of ventricular fibrillation were calculated by logistic regression. Tests for improvement in model fit were based on comparison of likelihood ratios. The tabulated likelihood ratios and $\mathrm{p}$ values are those which correspond to subtracting the corresponding variable from a model containing all other listed variables. Survival curves were generated by the Kaplan-Meier method, and survival probabilities are expressed as percentages with $95 \%$ confidence intervals (CIs). Subgroups were compared using the log rank test.

\section{Results}

TIME TO ADMISSION

Reliable information on time from onset of chest pain to hospital admission was available in 1193 patients (median admission time 2.02 hours; interquartile range 1.12 to 4.18 hours); $21.7 \%$ were admitted within one hour, $49.6 \%$ within two hours, $74.0 \%$ within four hours, and $94.2 \%$ within 12 hours (fig 1 ).

RATE OF VENTRICULAR FIBRILLATION

Ventricular fibrillation within 48 hours of the onset of chest pain occurred in $112(9.1 \%)$ of the 1225 patients. Analysis of the rate of ventricular fibrillation was based on the 1185 patients in whom its precise timing was known; 106 of these had ventricular fibrillation within 48 hours of the onset of chest pain. The rate of ventricular fibrillation was very high within the first hour and then fell rapidly (fig 2). Point estimates of the rate of first episodes of ventricular fibrillation $/ 1000$ persons/h were: 118 (95\% CI 50.7 to 231$)$ in the first hour; 27.0 (95\% CI 13.5 to 48.3 ) in the second; 32.2

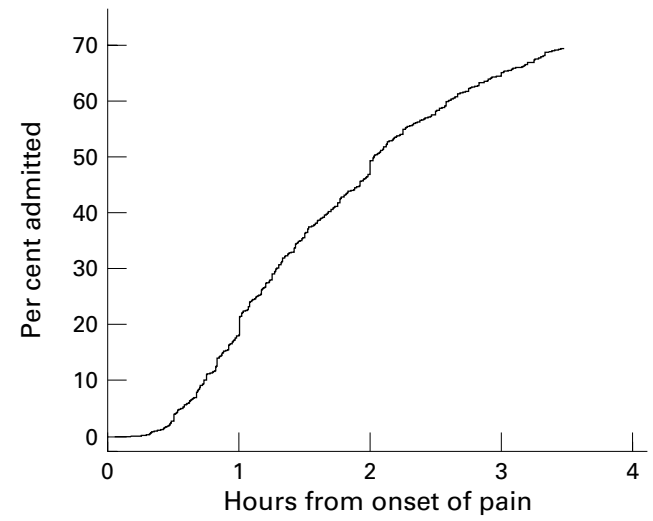

Figure 1 Cumulative distribution to time of admission after the onset of symptoms.

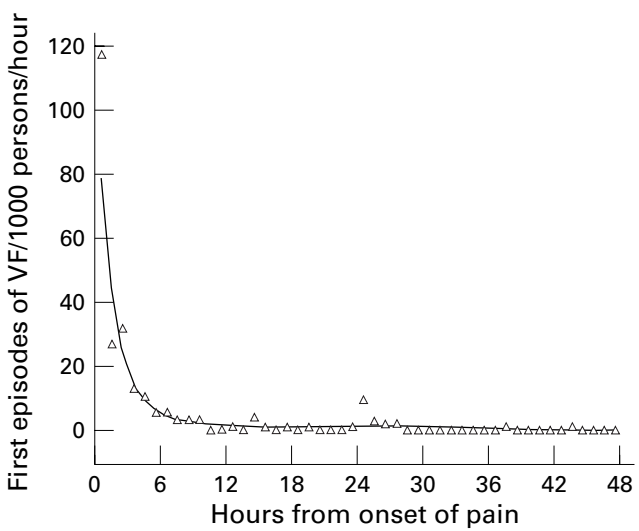

Figure 2 Point estimates (triangles) and regression curve (solid line) of the rate of ventricular fibrillation by hour from the onset of chest pain.

(95\% CI 19.9 to 49.2 ) in the third; and 13.0 (95\% CI 6.2 to 23.9) in the fourth. After six hours, the hourly risk of ventricular fibrillation had fallen to around 5/1000 persons/h and continued to decline slowly thereafter.

FACTORS ASSOCIATED WITH VENTRICULAR FIBRILLATION

Hypokalaemia (plasma potassium $<3.5 \mathrm{mmol} / 1$ from admission blood specimen) and left ventricular failure were both associated with a substantially higher risk of ventricular fibrillation, while patients with previous myocardial infarction and south Asians had a lower risk (table 2). Those admitted within two hours of the onset of chest pain had a substantially higher risk of ventricular fibrillation than those admitted later. Age, sex, and diabetes did not have a significant association with ventricular fibrillation.

PROGNOSIS

Hospital survival

The results are shown in fig 3. Of the patients who had ventricular fibrillation within 48 hours, $27.4 \%$ died in hospital, compared with $11.6 \%$ of those without early ventricular fibrillation (relative risk 2.36 (95\% CI 1.66 to 3.56); $\mathrm{p}<0.001)$. A higher proportion of those with early ventricular fibrillation had left ventricular failure $(47.2 \% v 32.8 \%$ in those without early ventricular fibrillation) and the relative risk of hospital death adjusted for left ventricular failure was 1.82 (95\% CI 1.32 to 2.52 ). 
Table 2 Multivariate predictors of ventricular fibrillation

\begin{tabular}{|c|c|c|c|c|c|}
\hline & $\begin{array}{l}\text { Odds } \\
\text { ratio }\end{array}$ & $95 \% C I$ & $\begin{array}{l}\text { Likelihood } \\
\text { ratio }\left(\chi^{2}\right)\end{array}$ & $d f$ & $p$ Value \\
\hline \multicolumn{6}{|l|}{ Race } \\
\hline White & 1 & & & & \\
\hline Asian & 0.41 & (0.22 to 0.77$)$ & 9.3 & 1 & 0.002 \\
\hline \multicolumn{6}{|c|}{ Previous myocardial infarct } \\
\hline No & 1 & & & & \\
\hline Yes & 0.44 & $(0.24$ to 0.79$)$ & 8.7 & 1 & 0.003 \\
\hline \multicolumn{6}{|c|}{ Hypokalaemia $(<3.5 \mathrm{mmol} / \mathrm{l})$} \\
\hline No & 1 & & & & \\
\hline Yes & 2.72 & (1.67 to 4.41$)$ & 15.0 & 1 & 0.0001 \\
\hline \multicolumn{6}{|c|}{ Left ventricular failure } \\
\hline No & 1 & & & & \\
\hline Yes & 2.30 & (1.49 to 3.55$)$ & 14.0 & 1 & 0.0002 \\
\hline \multicolumn{6}{|l|}{ Time to admission } \\
\hline$<2$ hours & 1 & & & & \\
\hline 2 to 3.99 hours & 0.50 & $(0.28$ to 0.88$)$ & & & \\
\hline $4+$ hours & 0.42 & $(0.24$ to 0.74$)$ & 12.7 & 2 & 0.002 \\
\hline
\end{tabular}

CI, confidence interval; df, degrees of freedom.
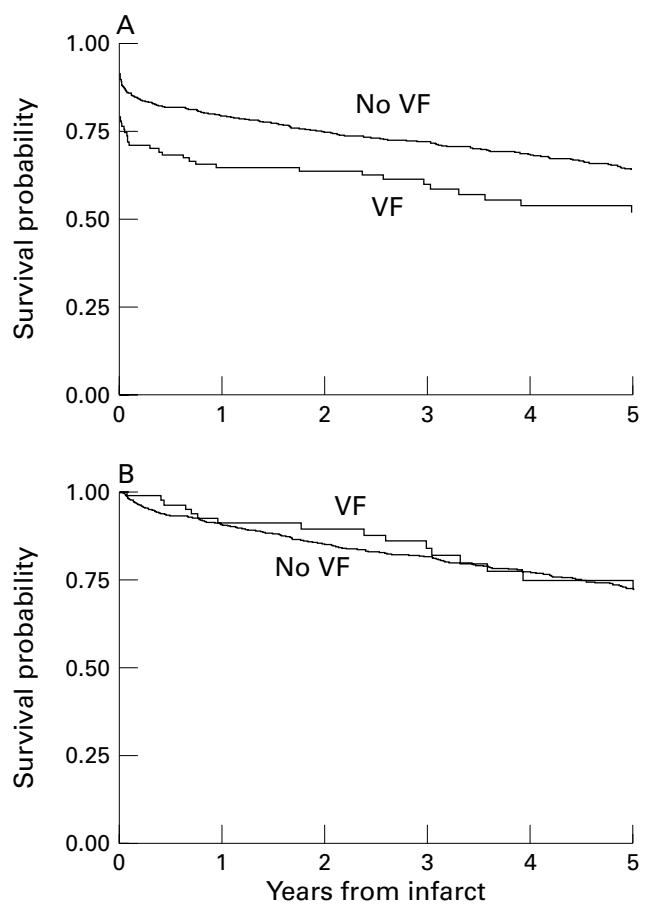

Figure 3 Survival from $(A)$ onset of chest pain and $(B)$ hospital discharge in patients with and without early ventricular fibrillation (VF).

Long term survival

Overall survival in patients who had early ventricular fibrillation was $66.7 \%(95 \%$ CI $56.8 \%$ to $74.8 \%)$ at one year and $54.3 \%$ (95\% CI $43.0 \%$ to $64.4 \%$ ) at five years, compared with $80.2 \%$ (95\% CI $77.7 \%$ to $82.5 \%$ ) and $64.6 \%$ $(95 \%$ CI $61.1 \%$ to $67.8 \%)$ in those without early ventricular fibrillation. However, the survival in patients discharged from hospital was virtually identical in the two groups: $92.1 \%$ (95\% CI $83.3 \%$ to $96.4 \%$ ) v $91.0 \%$ (95\% CI $89.0 \%$ to $92.7 \%)$ at one year and $75.0 \%(95 \%$ CI $60.6 \%$ to $84.8 \%$ ) v $73.3 \%$ ( $95 \%$ CI $69.6 \%$ to $76.6 \%$ ) at five years.

\section{Discussion}

In this study of a consecutive series of unselected patients admitted to a district general hospital we have shown that the risk of ventricular fibrillation in the first hour or so after acute myocardial infarction is very high and declines rapidly thereafter. Multivariate predictors of ventricular fibrillation included time to admission, hypokalaemia, left ventricular failure, and history of previous myocardial infarction, in line with the findings of other investigators. ${ }^{4-8}$ However, the observation that white patients were at greater risk has not been reported previously and warrants further investigation.

The prognosis in those resuscitated from early ventricular fibrillation was good and by hospital discharge comparable with that of patients without early ventricular fibrillation. The compelling public health message from our results is that clinical intervention in ventricular fibrillation can be very effective in terms of long term prognosis, but patients must reach expert medical care rapidly.

The need for rapid action is demonstrated by our estimate that more than half the episodes of ventricular fibrillation which occur within 48 hours from the onset of chest pain do so within the first hour. That the rate of ventricular fibrillation is very high early after acute myocardial infarction is confirmed by recent data from GISSI-2 (Gruppo Italiano per lo studio della sopravvivenza nell'infarto miocardico): among 7755 patients, $52 \%$ of episodes of primary ventricular fibrillation occurred within one hour of symptom onset. ${ }^{5}$ It is disappointing therefore that even in this urban setting only $21 \%$ of patients were admitted to hospital within one hour of the onset of symptoms. Admission rates are no faster in other city hospitals, ${ }^{1}$ and are almost certainly slower in rural settings, as evidence from the Grampian region and Auckland suggests. ${ }^{9}{ }^{10}$ We estimate that if admission times in our district were reduced to half an hour or less, around 90 patients of every 1000 who would otherwise have ventricular fibrillation out of hospital and die would be in hospital at the time of their first episode of ventricular fibrillation, and hence have a chance of resuscitation. Of these 90 patients, around 65 could be expected to survive to hospital discharge and 60 to survive one year. By comparison thrombolytic treatment has been estimated to save 20 to 30 lives/ 1000 patients treated within 12 hours of the onset of symptoms. ${ }^{11}$ Of course, lives saved through earlier hospital admission would also be complemented by additional lives saved through interventions to restore patency of the infarct related artery, which are considerably more effective if applied early after the onset of symptoms. ${ }^{12}$

Using data from the United Kingdom heart attack study, it has been estimated that 107 of 1000 lives (95\% CI 60 to 144 ) were saved for those coming under care for acute myocardial infarction within one hour of the onset of symptoms, compared with 21/1000 (95\% CI 5 to 37) for those who delayed more than 12 hours. Seventy per cent of this salvage was attributed to successful resuscitation. ${ }^{2}$ As a strategy for saving lives, therefore, early access to a defibrillator is potentially more effective than thrombolysis, especially given that in many centres only about $50 \%$ of patients with acute myocardial infarction are eligible for thrombolytic treatment. ${ }^{9}$ 
While the benefits of earlier access to a defibrillator in acute myocardial infarction are clear, the means of achieving this are not. Attention has largely been focused on the evaluation of out of hospital thrombolytic treatment $^{913}$ and fast track admission procedures, ${ }^{14-17}$ and relatively few studies have examined strategies to encourage earlier access to a defibrillator. The widespread introduction of defibrillators into the community and paramedic training in Seattle produced an early decline in mortality, ${ }^{18} 19$ but subsequently survival rates to hospital discharge have not improved. Evidence from the more recent introduction of paramedic training in this country suggests that the mortality from out of hospital ventricular fibrillation can be reduced, ${ }^{20}$ but this reduction is likely to be limited, ${ }^{21}$ and more immediate defibrillation would probably have a much more important impact. This requires patients to recognise symptoms and seek medical help promptly. ${ }^{22}{ }^{23}$

Various public education programmes have been tested, ${ }^{24-28}$ but a recent analysis concluded that although some of these reduced delays between the onset of symptoms of myocardial infarction and the time taken to reach hospital, this has not always been associated with improved survival..$^{29}$ Nevertheless, these programmes have rarely been applied for more than a year or two, and any benefits have inevitably been short lived. It is too early to conclude, therefore, that strategies of this type are ineffective, and consideration should be given to a sustained programme of patient education about the merits of early presentation in acute myocardial infarction.

LIMITATIONS

The rate of ventricular fibrillation in patients with acute myocardial infarction who die before hospital admission is unknown. It has been shown that three quarters of all deaths from acute myocardial infarction occur before hospital admission, and the majority of these are thought to be caused by ventricular fibrillation. In our analysis, we have assumed that the rate of ventricular fibrillation in those dying before hospital admission is the same as for those who survived to reach hospital. This gives an approximate but very probably conservative estimate of the additional lives that could be saved by early attendance at hospital.

\section{CONCLUSIONS}

In conclusion, rapid access to facilities for resuscitation is of paramount importance if a significant impact is to be made on the persistently high case fatality of patients with acute myocardial infarction. The evidence is very strong that many patients could be resuscitated and would have good long term survival if they could be brought more quickly to expert attention. This would be associated with additional benefits resulting from the earlier administration of treatment to restore antegrade coronary flow. The introduction of defibrillators into the community has had a limited impact, as have educational programmes. However, this should not inhibit the search for more effective solutions to this major cause of fatality in acute myocardial infarction.

1 Brown $\mathrm{N}$, Young $\mathrm{T}$, Gray D, et al. Inpatient deaths from acute myocardial infarction, 1982-92: analysis of data in the Nottingham heart attack register. BMf 1997;315:15964.

2 The United Kingdom Heart Attack Study (UKHAS) Collaborative Group. Effect of time from onset to coming under care on fatality of patients with acute myocardial infarction: effect of resuscitation and thrombolytic treatinfarction: effect of resuscitation

3 Norris RM, on behalf of the United Kingdom Heart Attack Study Collaborative Group. Fatality outside hospital from acute coronary events in three British health districts, 1994-5. BMF 1998;316:1065-70.

4 Lawrie DM, Higgins MR, Godman MJ, et al. Ventricular fibrillation complicating acute myocardial infarction. Lancet 1968;ii:523-8.

5 Volpi A, Cavalli A, Santaro L, et al, on behalf of the GISSI-2 Investigators. Incidence and prognosis of early primary ventricular fibrillation in acute myocardial infarctionresults of the Gruppo Italiano per lo Studio della Sopravvivenza nell'Infarto Miocardico (GISSI-2) database. Am F Cardiol 1998;82:265-71.

6 Brezins M, Elyassov S, Elimelech I, et al. Comparison of patients with acute myocardial infarction with and without ventricular fibrillation. Am f Cardiol 1996;78:948-50.

7 Chiriboga D, Yarzebski J, Goldberg RJ, et al. Temporal trends (1975 through 1990) in the incidence and case-fatality rates of primary ventricular fibrillation complicating acute myocardial infarction: a community perspective. Circulation 1994;89:998-1003.

8 Goldberg R, Szklo M, Tonascia JA, et al. Acute myocardial infarction: prognosis complicated by ventricular fibrillation or cardiac arrest. $\mathcal{F} A M A 1979 ; 241: 2024-7$.

9 GREAT Group. Feasibility, safety and efficacy of domiciliary thrombolysis by general practitioners: Grampian Region Early Anistreplase Trial. BMF 1992;305:548-53.

10 French JK, Williams BF, Hart HH, et al. Prospective evaluation of eligibility for thrombolytic therapy in acute myocardial infarction. BMF 1996;312:1637-41.

11 Fibrinolytic Therapy Trialists' (FTT) Collaborative Group. Indications for fibrinolytic therapy in suspected acute myocardial infarction: collaborative overview of early mortality and major morbidity results from all randomised trial of more than 1000 patients. Lancet 1994;343:311-22.

12 The GUSTO Investigators. An international randomized trial comparing four thrombolytic strategies for acute myocardial infarction. N Engl f Med 1993;329:673-83.

13 The EMIP Group. Pre-hospital thrombolytic therapy in patients with suspected acute myocardial infarction. NEngl F Med 1993;329:383-9.

14 Sharkey SW, Brunette DD, Ruiz E, et al. An analysis of time delays preceding thrombolysis for acute myocardial infarction. $\mathscr{F A M A}$ 1989;262:3171-4.

15 Ornato JP. Role of the emergency department in decreasing the time delay to thrombolytic therapy in acute myocardial infarction. Clin Cardiol 1990;13(suppl V):V48-52.

16 Cummings P. Improving the time to thrombolytic therapy for myocardial infarction by using a quality assurance audit. Ann Emerg Med 1992;21:1107-10.

17 McCallum AG, Stafford PJ, Jones C, et al. Reduction in hospital time to thrombolytic therapy by audit of policy guidelines. Eur Heart F 1990;11 (suppl F):F48-52.

18 Cobb LA, Hallstrom AL. Community cardiopulmonary resuscitation. Annu Rev Med 1980;31:453-62.

19 Cobb LA, Weaver WD, Fahrenbruch CE, et al. Communitybased interventions for sudden cardiac death. Circulation 1992;85(suppl I):I98-102.

20 Lewis SJ, Holmberg S, Quinn E, et al. Out of hospital resuscitation in East Sussex 1981-1989. Br Heart f 1993;70: citation

21 Rowley JM, Garner C, Hampton JR. The limited potential of special ambulance services in the management of cardiac arrest. Br Heart $\mathcal{7}$ 1990;64:309-12.

22 Herlitz J. The importance of reducing delay in acute myocardial infarction. Eur Heart $\mathcal{F} 1996 ; 17: 338-40$

23 Evans T. Cardiac arrests outside hospital: survival could be improved by better public awareness of symptoms. BMf 1998;316:1031-2.

24 Rowley JM, Hill JD, Mitchell JRA. Early reporting of myocardial infarction: impact of an experiment in patient education. BMF 1982;284:1741-6.

25 Gaspoz J-M, Unger P-F, Urban P, et al. Impact of a public campaign on pre-hospital delay in patients reporting chest pain. Heart 1996;76:150-5.

26 Herlitz J, Hartford M, Blohm M, et al. Effect of a media campaign on delay times and ambulance use in suspected campaign on delay times and ambulance use in suspected

27 Ho MT, Eisenberg MS, Litwin PE, et al. Delay between onset of chest pain and seeking medical care: the effect of onset of chest pain and seeking medical care: the

28 Mitic WR, Perkins J. The effect of a media campaign on heart delay and decision times. Can $\mathcal{F}$ Public Health 1984;74:414-18

29 Blohm MB, Hartford M, Karlson BW, et al. An evaluation of the results of media and educational campaigns designed to shorten the time taken by patients with acute myocardial infarction to decide to go to hospital. Heart 1996;76:430-4. 